\title{
International Postgraduate Students in Britain: Reasons for Studying Abroad and Issues Related to Adjustment
}

\author{
Yu-Yi Grace Chien \\ University of Exeter, $U K$
}

\begin{abstract}
This study investigates reasons for studying abroad and issues related to adjustment of first-year, full-time, postgraduate, international students at a southwestern UK university through a mixed methods research design. The research discovered that adjustment was a complex set of experiences. The value of overseas study, personal or family related factors, lack of opportunities at home, and financial or promotional reasons were main motivators for study abroad. International Postgraduate students tended to pay more attention to academic than socio-cultural adjustment because personal agency and cultural identity operated more explicitly in socio-cultural than academic adjustment. Additionally, the data reveal that both acculturation and hybridization accounted for the processes that inform students' socio-cultural adjustment.

The push-pull model is more applicable than the Theory of Planned Behavior in explaining reasons for studying abroad. Maslow's Hierarchy of Needs Theory is less relevant to adjustment investigation because international students tend to have special characteristics and their satisfaction perceptions are guided by various cultural factors. Finally, the $U$ curve hypothesis is not supported by the research data, as methodological issues, different internal and external factors, cultural expectations, individual responses or attitudes, and technological and world development have the potential to impact on adjustment.
\end{abstract}

\section{Introduction}

Universities have become increasingly international institutions. The aim of this study is to understand how this trend is experienced by international students themselves. This research mainly studies what factors motivate first-year, fulltime, postgraduate, international students to pursue an overseas education at a British university and the relevant issues associated with adjustment. The context in which this study was undertaken is a university in South West England. To preserve its anonymity, this university will be referred to as University South West (USW) throughout the study.
The internationalization of higher education has led to a number of benefits worldwide. These benefits include increasing the quality of education, contributing to the economies of the host countries, and fostering international communication and understanding. Britain is one of the leading destination countries recruiting international students for its tertiary education. Research [1] reports that the internationalization of the UK tertiary education benefits the British economy, the entire Britain as a host, international graduates as alumni, and international students' countries of origin. According to the Higher Education Statistics Agency [2], among "2,299,355 students in higher education in Britain in 2013/14, 125,300 (5.5\%) were from other EU member countries and 310,195 (13.5\%) were from non-EU countries." China, India, Nigeria, Malaysia, and the United States were the top five non-EU countries of origin. Non-UK students represented almost $19 \%$ of the total student population in Britain. The estimate of non-UK higher education students' contribution to the UK economy, including tuition fees and living expenses, was about £7.9 billion for 2009 [3]. The future economic contribution is estimated to be approximately $£ 16.9$ billion by 2025 .

The history regarding international students in Britain can be tracked back to the medieval period when multinational visitors or students studied in British universities [1]. The 1991 Education Act, the 1999 Prime Minister's Initiative (PMI), and the PMI 2 programme in 2006 are recent examples of educational policies implemented for the development of the UK international higher education and the establishment of 'the Education UK brand. A report from Universities UK [3] indicates that characteristics, including "an international reputation for education and research, the profile of its elite global higher education brands, historical trade and political links, the popularity of English language study and culture, [and] post-study employment prospects" (p.12), benefit Britain's competition in recruiting international students for its higher education. "(1) [T] he existence of a high standard of universities based on a national quality assurance system, (2) the short length of degree 
programmes and (3) the UK's long-standing history of solid higher education institutions (p.273)" are important features attracting international students to choose Britain as a study-abroad destination country [4]. However, weather could deter prospective students from studying in Britain.

USW was chosen as the study site because it has been dedicated to increasing its own international reputation; in addition, it has a large international student population from over 140 countries. USW is a member of the Russell Group of leading researchintensive universities. Its vision is to be a prominent international university, recognized by the quality of its global research and the distinctive student experience that it offers. The International South West Annual Report 2011-12 [5] indicated that the success of international student recruitment enables USW to reinvest in more and wider activities related to the internationalization of higher education.

The special features of this study include a mixed methods research approach, a British university setting, and a comprehensive examination of reasons for studying abroad together with a consideration of both academic and socio-cultural adjustments of postgraduate international students. The research design and its findings are also expected to contribute to a more complex and nuanced understanding regarding the application of relevant theories or hypotheses to a particular British educational context. This research aims to contribute to academic knowledge in the relevant fields, to inform practical international student support services, and to contribute to an understanding of the internationalization of higher education in Britain, in the context of an academic environment that seeks to foster global cooperation and communication.

\section{Literature review}

In this section, definition of key concepts, existing empirical research on reasons for studying abroad, factors associated with international students' adjustment, and the relevant theories and models are mainly reviewed as follows:

\subsection{Definition of important concepts}

A number of key concepts, which are used throughout the research and literature review, are reviewed and defined below. Firstly, because of the special situation in Britain, as one of the European Union (EU) members, the term 'international student' in this study refers to any student who is not a British citizen or permanent resident, although, traditionally, researchers have defined an international student as one who enrolls and studies at a foreign higher education institution with a temporary student visa, in other words, a student who is not a citizen, permanent resident, illegal immigrant, or refugee of a host country [6]. Secondly, after referencing research [7], adjustment is delineated as a process of change or adaptation in response to the situation or environment a person finds themselves in. Academic adjustment is interpreted as the fitting process of how students conform to an academic environment [8]. Sociocultural adjustment is defined as the fitting process of how individuals get used to a new culture or society [9]. Burnapp [10] indicates 'hybrid' (third space) as an option or alternative for temporary sojourners to adjust to a new environment by creating a new space, including insiders and outsiders, and allowing sojourners to develop and discover themselves and have their own space. Although acculturation is a concept different from hybridity or hybridism in relation to a sojourner's adjustment process [10], it is articulated as the adjustment of a person or group living or experiencing a different culture [11].

The preceding descriptions regarding the meaning of different concepts serve not only to clarify terms but also to facilitate the further investigation and relevant comparison associated with the potential relationship between some concepts.

\subsection{Empirical research on reasons for studying abroad}

Today studying abroad takes place in a context of increased internationalization within the higher education sector. Additionally, reasons for studying abroad are complex and interconnected. Generally, a prospective international student's choice of a destination country for overseas study is usually made based on the match of his or her personal needs, situations, networks, and factors related to academic requirements, educational services, educational advantages or benefits, and living environment in a host country. This research defines reasons for studying abroad as the factors mainly motivating one's decision to pursue an overseas education. The following literature reviews relevant empirical research based on seven categories.

2.2.1. Political reasons. National policies [12] or political situations [13] in home country may motivate one to study overseas although these factors do not directly arise from one's internal desires.

2.2.2. Economic reasons. Economic reasons regarding a sending country, such as economic 
situation, labor market [13], and salary structure [14]; or regarding an individual, such as increasing employment opportunities [15], and the costs, funds, or financial support (scholarship) for studying abroad [16] can affect one's study-abroad decision.

2.2.3. Personal reasons. Personal improvement [15] or becoming more professional [17], immigration plans [18], influence from significant others [19], broadening social networks [20], previous travel experiences or intention to travel [21], marital status [18] or family commitments [16], and language acquisition for improving global competence [15] are examples of personal reasons for studying abroad.

2.2.4. Educational reasons. Educational factors, such as educational accessibility [13] and quality [15], may influence one's intention for studying overseas. The difficulty of the U.S. university application process [13] and different admission requirements can be reasons for choosing to study in Britain [19]. Differences in educational training and methods, better futures or visions for postgraduate education [22], and an excellent educational environment [13] can also be motivators.

2.2.5. Cultural reasons. Cultural reasons, such as increasing intercultural sensitivity, broadening multicultural experience [13], and gaining an international network or perspective [23] are influential factors for studying abroad.

2.2.6. Informational reasons. Informational reasons, such as information availability, perception, and accessibility, usually play a role in pulling or encouraging one to study overseas, so impressions and informational resources importantly affect one's choices of where for overseas study [19]. What educational information and how one can receive the relevant information should be emphasized for improving student recruitment.

2.2.7. Environmental reasons. Environmental reasons, such as comfortable weather and safe or low-crime areas, also importantly influence some international students' choice of a destination country [24]. Usually, except for low temperature, environmental reasons in a host country are the same or better than those in a sending country.

In the context of this study these reasons were considered both in relation to how they were reflected in the views of the research participants as well as how original motivations informed subsequent adjustment. The above literature review not only benefits the qualitative interview investigation related to reasons for studying abroad, in Britain, and at USW but also the construction of the quantitative online questionnaire survey.

\subsection{Existing research on factors related to international students' adjustment}

The following discussion illustrates issues related to international students' adjustment to a host learning environment. These influential factors are grouped into six categories and reviewed as follows:

2.3.1. Personal factors. Gender [25], age [26], personality-related issues [27], marital status [28], ethnicity [8], motivation for transition [29], finance, religion [30], and social support [31] compose the personal factors influencing the adjustment of international students. In relation to how students feel themselves perceived, a perception of discrimination [32] and homesickness, perceived fear, stress caused by change and cultural shock, or other relevant miscellaneous factors [33] are also found to associate with their adjustment.

2.3.2. Academic factors. Academic factors, such as academic preparation [34], language proficiency or acquisition ability [35], and learning skills or skills for success [36], are discovered to relate to the adjustment of international students.

2.3.3. Cultural factors. Cultural factors associated with adjustment include cultural similarity or dissimilarity [33] and attachment to home culture [37]. Generally, cultural similarity plays a positive role: if the cultural gap or dissimilarity between one's home and the host cultures is big, one tends to experience more stress or difficulties and need more time or effort for adjustment.

2.3.4. Factors related to a host country. Friendship and interaction with host members [38], host environment receptivity [39], and engagement with the host country [37] relate to a host country and positively influence adjustment. However, prejudice toward minority sojourners because of the skin color or other physical traits may negatively impact the degree of minority sojourners' acculturation into the host environment [40].

2.3.5. Residential factors. Residential factor influencing adjustment include length of residence [38] and accommodation [39]. In general, length of residence is a positively influential factor.

2.3.6. Factors related to student support services. Factors related to student support services include international student support programs [41], and school administration or services for international 
students [30]. However, Surdam [32] found that orientation programs and participation in university and community activities did not significantly influence international student adjustment. Therefore, further relevant research is still needed.

In analyzing the data for this study, previous research was considered informative in identifying those factors influencing adjustment, but the intention was also to see these factors in relation to each other. This was especially the case regarding the two key foci for adjustment: academic and sociocultural. The aim of the study therefore was not to categorize adjustment but to understand the complex relationship between categories.

\subsection{Relevant theories and models}

In this study, the push-pull model and the Theory of Planned Behavior (TPB) are referenced for the discussion related to reasons for studying abroad. The U-curve Hypothesis and Maslow's Hierarch of Needs Theory are applied to examine issues regarding adjustment.

2.4.1. The push-pull model. The push-pull model states that various influential factors may 'push' and 'pull' students to leave their home country and go to another country for studies. 'Push' elements usually "operate within the source country and initiate a student's decision to undertake international studies;" 'pull' elements often "operate within a host country to make that country relatively attractive to international students" (p. 82) [42]. Research by Mazzarol et al. [24] regarding how Chinese students selected a destination country showed that 'push' (the economic, social and political forces within China) and 'pull' (characteristics within a host country) factors importantly affected Chinese to study overseas. Increasing knowledge and understanding of the Western culture, followed by the consideration regarding the better quality of an overseas education, played the most important pulling role.

2.4.2. The Theory of Planned Behavior. TPB is used to explain one's decision making for studying abroad from the perspective of a rational consumer. The theory supposes that one's decision or intention is composed of three elements (attitudes towards behavior, subjective norms, and perceived behavioral control), which are also associated with six factors regarding contextual considerations [19]. TPB, viewing students as consumers in a tertiary education marketing context, states that examining attitudes and their following intents or objectives is the prerequisite for understanding one's choice behaviors. Therefore, there should be a link between human behaviors and beliefs, attitudes, or intentions. 2.4.3. The U-curve Hypothesis. The U-curve hypothesis is often used to describe sojourners' cultural adjustment. It was first introduced by Lysgaard [43] in his study of Norwegian Fulbright scholars in the U.S. Oberg [44] used 'honeymoon,' 'crisis,' 'recovery,' and 'adjustment' to illustrate the four stages of this hypothesis. However, more recent and comprehensive research has indicated that support for the U-curve hypothesis is limited [45] and the evidence for it is "weak, inconclusive and overgeneralized" (p. 542) [46]. Given the preceding description, it would be worthwhile to re-examine the relevant issues, especially because the hypothesis has held a central position in research and theory on transition and adjustment.

\subsubsection{Abraham H. Maslow's Hierarchy of Needs} Theory. Maslow [47] categorizes human beings' five basic needs in his Hierarchy of Needs Theory. From the lowest to the highest order, they are: physiological needs, safety needs, belongingness and love needs, esteem needs, and the need for selfactualization. Homeostasis is the state that individuals seek to gratify themselves. Maslow refers to the phenomenon of new higher needs emerging after the gratification of the lower needs as a hierarchy: "the basic human needs are organized into a hierarchy of relative prepotency" (p. 17) [48]. Once the lower basic or prepotent human needs are satisfied, the needs become insignificant in the dynamics of the need hierarchy. Individuals with higher need satisfaction usually have greater happiness, peace, and fulfillment [47]. However, more prerequisite and better circumstances are required for the gratification of higher needs.

The aforementioned research concepts, empirical studies, and theories or models outline and interpret the possible explanations for issues or phenomena related to this study. However, the applicability of these concepts, studies, and models or theories to this research still needs to be examined through the empirical data collected and analyzed based on the research design of this study, which is articulated in the following section.

\section{Research methods}

This research is a mixed methods project. Two qualitative semi-structured interviews and a quantitative online questionnaire survey were conducted for research data collection. Mixed methods research is a design that applies two or more methods [49] of both qualitative and quantitative data collection and analysis. It is a more 
comprehensive, elaborate, and practically useful approach offsetting the inadequacy of a single approach alone and offering diverse views for question investigation [50].

Ontology, epistemology, and methodology matter for social science research and the production of knowledge because they are three important dimensions in the philosophy of science: ontology is concerned with objects; epistemology discusses issues related to knowledge or theories; methodology is related to methods or practices [51]. This study takes a pragmatic approach: it accepts causal reality but views the social context as key to understanding the experiences of international students and the meanings they construct from these experiences. This approach has informed the adoption of a mixed methods design. From an ontological viewpoint, the knowledge associated with this study is derived from human interest, action, and interaction among international students and relevant people, such as schoolteachers, administrators, policy makers, and government officials. Epistemologically, pragmatism is concerned with the practical resolution to problems [52]. Pragmstist researchers tend to use applicable pluralistic, multiple, or mixed methods approaches to uncover knowledge and answers to human questions and problems [53].

This research uses a sequential exploratory strategy, one of the four mixed methods designs suggested by Creswell [54]. This strategy is an approach with qualitative data collection and analysis conducted initially, followed by a quantitative phase. The findings from the two methodological aspects are then integrated into the final research interpretation. Although it often takes a lot of time to conduct two phases of methodology, this strategy is advantageous to the construction of a new instrument (as the online questionnaire in this study) and the exploration of a phenomenon with the expansion on more qualitative findings.

This research seeks to answer the following questions:

- What are the reasons that motivate the research participants to study abroad?

- How does the experience of studying and living in Britain compare to their initial expectations? For instance, are the research participants' expectations or reasons for an overseas education changed after coming to Britain?

- What are the academic experiences of the research participants in a British university?

- Especially, what do they think about their study programs, learning resources, and various issues related to their learning activities?

- What are the socio-cultural experiences of the research participants?
- Especially, to what extent, are these research participants able to adjust well to the socio-cultural life of a British higher education institution?

- Can the U-curve hypothesis be applied to explain the adjustment of the participants in this research?

- Can Maslow's Hierarchy of Needs Theory be applied to explain the situation of the participants?

Two interview schedules and an online survey questionnaire, named as International Student Adjustment Survey (ISAS), were designed to address and answer the relevant research questions. The constructs of ISAS include data collection regarding demographic characteristics, reasons for studying abroad, academic adjustment, socio-cultural adjustment, and overall adjustment. ISAS was developed based on the previous literature review and the qualitative fieldwork from the two face-toface in-depth semi-structured interviews employed at the middle of the Autumn (October and November in 2010) and Spring (February and March in 2011) Terms. The interval between terms was, on average, three months. From May 17, 2011, the questionnaire was formally distributed to all research subjects via an email with a follow-up email.

The research population only includes first-year, full-time, postgraduate, international students studying at a southwestern British university during the 2010-11 academic year. The quantitative research sampling frame was the same as its population. 250 respondents anwered the questionnaire. For the qualitative phase, twenty-six students were purposefully sampled (sampling for heterogeneity as defined by Tashakkori and Teddlie [53]) as the participants based on the maximum heterodoxy of the students' background demographic characteristics (such as gender, degree of study, study field, and geographic area of origin).

Through findings based on different samples drawn from the same research population, this mixed methods design provides an exploration of group trends combined with more in-depth personal reflections. The qualitative interview data allowed this research to examine information from the micro level and to investigate the changing process of the student adjustment from a longitudinal perspective. The quantitative questionnaire data offered the macro information from a larger sample and helped discover whether any significant differences existed between the interviews and online survey and whether their findings were consistent.

Additionally, during the second interview, one evaluative task was designed to examine interviewees' adjustment situation (related to the visual investigation of the U-curve hypothesis) and how satisfied they were with various adjustments and life needs during their study-abroad period. Finally, 
a self-evaluation form regarding monthly adjustment was also implemented to numerically investigate the adjustment process of the interviewees and to see whether it mirrored the U-curve hypothesis.

\section{Analysis of research findings}

Based on the research data, findings are analyzed as follows:

The qualitative interview data related to international postgraduate students' reasons for studying abroad are grouped into four categories: the value of overseas study, personal or family-related factors, lack of opportunities at home, and financial or promotional reasons. More specific reasons for studying in Britain include: geographical, cultural, and historical reasons; finances; personal or familyrelated reasons; educational quality and opportunities; and admission requirements. Reasons for studying at USW include: study- or interestrelated reasons, ranking and reputation, environmental reasons, personal reasons, and finances. Most of the quantitative questionnaire findings are generally consistent with the qualitative interview findings.

Cultural dissimilarities tended to make Asian students feel greater differences between British and the individual home cultures. Most of the interviewees had the same reasons for studying overseas before and after arrival. However, new learning, perspectives, and opportunities could change students' reasons for studying abroad. Most of the interviewees had positive both study-abroad first impressions and future expectations toward both their academic and socio-cultural experiences. These findings generally show that students experience a good start in their student life and hold optimistic hopes for later studying abroad experiences.

The research findings regarding academic adjustment show that USW generally is a very good learning environment with sufficient available academic resources, respect for cultural diversity, and an emphasis on the student-teacher relationship. However, issues regarding teaching styles and engaging with the academic community still challenge USW's future development and its efforts to ease the adjustment difficulties of international students. The findings related to the positive adjustment of the interviewees generally support and are consistent with the findings discovered from the quantitative questionnaire survey.

For most of the international students, it is very natural that difficulties occur during the academic adjustment process. Academic writing and criticality in thinking and questioning were the top two difficulties that most of the international postgraduate students faced based on the quantitative survey data. The peers of international students, the university support mechanisms, and teachers played important roles in the process of solving difficulties. Based on the quantitative survey findings, there was a slightly higher tendency among international postgraduate students to ask for academic assistance from their colleagues or classmates. It was especially important and helpful that the university and its staff welcomed international students and encouraged them to share their problems and ask for assistance. Sufficient and proper support also resulted in more satisfactory academic experiences for most of the international students.

Findings regarding socio-cultural adjustment suggest that the local British cultural engagement and interaction with local British people need to be improved and encouraged because most of the participants tended to interact with and ask for help from people from the same home country. Although language or communication skills and host cultural engagement were socio-cultural difficulties for some students, participation in religious activities or student clubs or societies appeared to benefit the host cultural engagement. The question of why students were more likely to rely on people from the same home country or with a similar cultural background during their socio-cultural adjustment process is worth further investigation.

Most of the interviewees had an open attitude toward local British culture or society but they still preferred to maintain their own cultural values, traditions, or life style. This preference indicates that cultural identity tends to be shaped over a longer time period; students experience something new but they also like to remain who they are. The positive effect of USW's Welcome Week services suggested that educational institutions could help international students with better social, cultural, or institutional adjustment through well-organized orientation programs or support services from the beginning of their university career. Sharing the feelings with friends or peers with similar experiences or cultural backgrounds importantly influenced international students' choices and acted as a support mechanism in their socio-cultural adjustment. This finding also indicates that academic adjustment may not have been easy but the need to adapt is more pressing than for socio-cultural adjustment. International students made more efforts at academic adjustment than socio-cultural adjustment so they generally were more satisfied with their academic progress than their progress in socio-cultural adjustment.

Relating to the U-curve hypothesis, the appropriateness of this for understanding adjustment is not demonstrated by most of the empirical 
evidence collected in this study, since international students usually encountered a more complex set of experiences while studying abroad. Students' monthly self-evaluation of their various adjustment processes also does not support the hypothesis. Various factors were suggested by the interviewees for explaining the lack of relevance of the hypothesis to this research; but issues related to research methods could also contribute to the explanation. Finally, the research data do not support Maslow's Hierarchy of Needs Theory, suggesting that this cannot be applied to explain the satisfaction of international postgraduate students in this research. Both qualitative and quantitative data revealed that international students at USW were generally most satisfied with their safety needs regarding the local environment. However, with regard to those needs least met during their stay in Britain, the qualitative data differ from the quantitative data, in that in the case of the former, the least met need was belongingness and love, whereas for the latter, it was self-actualization.

\section{Discussion}

This research reveals that the adjustment of international students is a complex phenomenon that does not fit easily with attempts to define and categorize it. This section discusses the research findings and their implications from different aspects as follows:

\subsection{Reasons for studying abroad}

The value of overseas study, personal or family related factors, lack of opportunities at home, and financial or promotional reasons are identified as the main reasons why international students choose to study abroad. Most of the students' reasons for studying abroad remained the same before and after studying in Britain: lack of opportunities at home and financial or promotional reasons remained constant throughout the data collection period, but motivations regarding the value of overseas study and personal or family-related factors changed after students experienced the host context. 'Desiring job promotion' in the category related to financial or promotional reasons based on the qualitative data is viewed as a new finding, which is slightly different from the existing topic in the literature associated with becoming more professional [17]. Additionally, the push-pull model is discovered as more applicable than the Theory of Planned Behavior in explaining reasons for studying abroad as the research findings are more easily and conveniently illustrated by both 'push' and 'pull' dimensions of the model. In the qualitative interview section, students' reasons for studying abroad, in Britain, and at USW, are different; however, both financial and personal reasons consistently influence these three different types of decision-making, indicating the prevalence of social factors as the 'push' element from the home context. Both qualitative and quantitative research findings generally confirm the existing findings presented in the literature review, including political, economic, personal, educational, cultural, informational, and environmental reasons. Most of the international students have more academic expectations compared to more socio-cultural reasons for studying abroad.

Finally, findings related to reasons for studying abroad, in Britain, and at USW provide beneficial information for future student recruitment because higher education authorities can provide attractive incentives, such as scholarships, and proper supportive services, such as community engagement opportunities, in order to meet students' various needs. Additionally, being able to make a comparison between the qualitative and quantitative findings regarding reasons for studying abroad, in Britain and at USW, demonstrates one of the advantages regarding selecting the qualitative and quantitative research participants from the same research population.

\subsection{Academic adjustment}

Academic adjustment is usually unavoidable and generally exerts stronger influences than sociocultural adjustment because academic studies play a central role in students' overseas education. Based on the research findings, students were more likely to do their best to face and adjust to internal or external academic challenges because they finally would be evaluated based on the academic performance. Therefore, academic adjustment was the area in which students experienced the most difficulties and had the least personal agency and cultural identity because of the educational accountability required, based on the more standardized criteria. Some students even saw academic difficulties positively, as challenges for self-improvement. Generally, they had positive first impressions, expectations, experiences, and performance for their academic adjustment, even though they experienced difficulties initially. Some academic experiences met students' earlier expectations, and this situation also caused greater academic satisfaction. Language issues are common difficulties for students whose native language is not English. Many academic challenges or difficulties usually associate with students' competence with the host language. 
Academic writing, class discussion, criticality, and presentation are also difficulties caused by cultural dissimilarities or learning differences, but teachers or official university resources and friends or colleagues are beneficial support mechanisms for problem solving. Engagement in the academic community is highlighted as an area that needs improvement both in terms of how this is supported by the institution and in how this is taken up by international students. Finally, type and length of studies also affect academic adjustment because more intensive and independent skills are required in British education, but these requirements are different from many students' undergraduate experiences or learning styles practiced in home countries.

The research findings imply that international postgraduate students' feeling a part of the USW academic community needs to be improved, and that peer-study partnership can become more efficient in order to help them achieve better academic community engagement. Both international students and teachers need to adjust to each other, in regard to the teaching, guiding, and learning styles. University faculty can also assist students to adjust better through being familiar with students' adjustment needs and encouraging them to use the available university resources. A creative synergistic approach could also be adopted for improving mutual respect and cultural understanding between teachers and international students.

\subsection{Socio-cultural adjustment}

Most of the interviewees had positive first impressions, expectations, and actual experiences about their socio-cultural adjustment. Language issues, the same as academic adjustment, still bothered some students in socio-cultural adjustment but difficulties were mainly in developing communication skills and understanding local accents. Coping with cultural differences, local cultural engagement, and interaction or friendship with host nationals were also found to be sociocultural challenges. Both personal agency and cultural identity are significant here in shaping sociocultural adjustment, with fewer intentions to initiate changes, because international students are temporary residents with weaker or minor desires to acculturate to the host country but with a stronger commitment to maintaining their original cultural heritages. This finding is slightly at odds with students' original reasons for studying abroad, which cite cultural engagement as an influential motivator. Most of the research participants tended to experience an international postgraduate student culture' as defined by Wu and Hammond [55], have more interaction with people from the same home country, and prefer their cultural heritages or home life styles even though they were open to sociocultural adjustment, and some also had opportunities to interact with host nationals through shared accommodation, personal leisure activities, or religious services. Some students even questioned whether it was necessary and important for them to have local cultural interaction when they did not feel comfortable about it. Cultural similarities, religion, and student clubs or societies benefited sociocultural adjustment, although a heavy study workload might reduce the time for socio-cultural engagement. Finally, international students were found to exemplify both acculturation and hybridization in the experiences and choices of their socio-cultural adjustment. They face relatively fewer socio-cultural difficulties and have a wider range of attitudes, options, or responses to the difficulties because diverse outcomes and resisting the process of acculturalization are usually acceptable. These findings also reveal that international students generally are very rational and able to analyze and compare both the advantages and disadvantage of various cultural differences and then make the decision to accept or reject new things in the host country.

The above research findings imply that, with generally good adjustment, international students' interaction with host nationals needs to be improved because host friendships and cultural experiences benefit both international students [56] and the local people, and should be part of the studying abroad experience. Findings related to the first UK impressions and cultural dissimilarities suggest that Asian students may need more resources or assistance in order to increase their understanding of European culture because they tend to perceive greater cultural dissimilarities. The positive sociocultural findings generally demonstrate Britain as a good destination country for studying abroad.

\subsection{Theories and issues regarding studying abroad}

The insufficient applicability of Maslow's theory to this study can be understood by two possible explanations discovered by this research: first, the fact that international students are a different population with special characteristics, and second, the fact that cultural factors may primarily affect their need satisfaction. Furthermore, the relationship between challenges and motivations is still more complex than what a linear set of needs may explain because challenges and motivations may also interact 
with each other. Additionally, students' experience is not best accounted for by the U-curve hypothesis, which states that culture shock is first experienced and then accommodated by adaptation, because the student participants usually appear to encounter a more complex set of experiences influenced in various ways by different internal and external factors, different cultural expectations, and the student's adaption, negotiation, and resistance to social norms in the host context. Methodological issues, different internal and external factors, cultural expectations, individual responses or attitudes, and technological and world development were discovered as causes associated with this finding. Thus, traditional models can be challenged in the light of the complex forces informing adjustment. Even when students voice positive attitudes, the qualitative data reveal tensions and a variety of ways in resolving these tensions. Students or people from the same home country play a helpful role, especially with initial socio-cultural adjustment; however, people from the same home country may hinder students' host cultural engagement and interaction with students from other countries. Finally, the data reveal that international students are not a homogenous community and that their differences require different kinds of adjustment and support. For example, married female international students were discovered to need more support in time management and child-care issues.

The findings related to Maslow's theory imply that support services for international students should consider their special needs and be aware of cultural factors or language issues that may dominate their adjustment. The research data also imply that international students probably care more about mutual cultural understanding and respect between themselves and host nationals, so they may need more assistance in increasing their interaction with host nationals and improving their involvement or engagement within the local or academic communities. Finally, the findings related to the Ucurve hypothesis imply that cultural shocks do not play a major role in student adjustment in this study, and that the adjustment process of international students nowadays, after globalization, high-tech and transportation development, and the internationalization of higher education, is not enough or adequately explained by the hypothesis.

\section{Conclusion}

Practical recommendations are included for constructive contributions. This research is expected to be beneficial for future research related to international higher education, practices in international student support services, and policies regarding the internationalization of higher education.

\subsection{Recommendations for future research}

More research will be expected to contribute to more relevant understanding, practices, and policies. Firstly, in relation to research subjects, university staff or faculty associated with international students or their relevant support services could be included because their information can provide another perspective in understanding the adjustment and needs of international students, which is different from information collected from international students themselves. Additionally, future research could investigate international students from more diverse backgrounds (such as undergraduate students or students in short-term language study programs) and focus on groups that are different from volunteers. This may help researchers discover negative and perhaps more insightful findings that are closer to a larger body of students' actual experiences. Furthermore, future research can be conducted for a longer period than this research, which may help researchers discover more varied issues related to the change or development of international students' adjustment.

\subsection{Recommendations for future practice}

Some relevant issues for the further practices in the field are also recommended. For instance, university authorities can provide more language support or academic proofreading services for international students as they need to improve their academic performance and English skills. In addition to sufficient and reasonably priced accommodation, international students should be permitted and encouraged to arrive at the university earlier for better adjustment preparation. Furthermore, international students and host nationals should be encouraged to have more interaction with each other. They should also be encouraged to participate in student clubs or activities and to use the available university resources. Finally, student support services can be improved through more professional job training to university staff, more friendly students-centered services, and increasing knowledge and understanding regarding the difficulties and needs of international students. With more thoughtful attention and cultural understanding, students' wellbeing can be ameliorated with greater success. 


\subsection{Recommendations for future policy}

Since studying abroad has more advantages than disadvantages and benefits international students and a host country, policies regarding attracting more students to study in Britain, such as scholarships or financial support, should be continued and even improved for increasing the mutual understanding among people in the world. Finally, in relation to the length of study, a one-year Masters program is not popular with all international students, as although some appreciate the length of one year for financial and timing considerations, others also hope to have more time for robust learning and training. Therefore, how to decrease the disadvantages of this situation and how to use its positive special characteristics to recruit more international students to study in Britain present challenges to educators and policy makers.

\section{References}

[1] R. Mellors-Bourne, C. Humfrey, N. Kemp, and S. Woodfield, "The wider benefits of international higher education in the UK", (BIS Research Paper number 128), retrieved from: https://www.gov.uk/government/uploads/system/uploads/a ttachment_data/file/240407/bis-13-1172-the-widerbenefits-of-international-higher-education-in-the-uk.pdf, (Accessed: 28 February 2014), 2013.

[2] Higher Education Statistics Agency (HESA), "Free online statistics - students \& qualifiers", retrieved from: https://www.hesa.ac.uk/stats, (Accessed: 24 May 2015), 2014.

[3] Universities UK, "Futures for higher education: Analysing trends", retrieved from: http://www.universitiesuk.ac.uk/highereducation/Documen ts/2012/FuturesForHigherEducation.pdf, (Accessed: 28 February 2014), 2012.

[4] M. Toyoshima, "International strategies of universities in England", London Review of Education, 2007, pp. 265280.

[5] The University of South West, "International South West annual report 2011-2012", retrieved from: http://www.southwest.ac.uk/media/universityof southwest/internationalsouthwest/pdfs/infoforstaff/Internat ional_SouthWest_Ann_report_11-12-LOW-

SPREADS.pdf, (Accessed: 4 July 2013), 2013.

[6] Institute of International Education, Open Doors 2005: Statistics on International Student Mobility, Institute of International Education, Washington DC, 2005.

[7] Pedersen, P., The Five Stages of Culture Shock: Critical Incidents Around the World, Greenwood, Westport, C.T., 1995.

[8] B. Rienties, S. Beausaert, T. Grohnert, S. Niemantsverdriet, and P. Kommers, "Understanding academic performance of international students: The role of ethnicity, academic and social integration", Higher Education, 2012, pp. 685-700.
[9] Udoh, B.O., Cultural Adjustment of Foreign Students in an Institution of Higher Education, Unpublished doctoral dissertation, Louisiana State University, Available from: ERIC Document Reproduction Service (ED464560), 2000.

[10] D. Burnapp, "Trajectories of adjustment of international students: U-curve, learning curve, or third space", Intercultural Education, 2006, pp. 81-93.

[11] Y. Zhou, S.D. Jindal, K.K. Topping, and J. Todman, "Theoretical models of culture shock and adaptation in international students in higher education", Studies in Higher Education, 2008, pp. 63-75.

[12] Atai, M.F., The Sending of Iranian Students to Europe, 1811-1906, Doctoral dissertation, Available from: Dissertation Abstracts International Database (AAT 9304855), 1993.

[13] F. Maringe, and S. Carter, "International students' motivations for studying in UK HE: Insights into the choice and decision making of African students", International Journal of Educational Marketing, 2007, pp. 459-475.

[14] N. Syed, F. Khimani, M. Andrades, S. Ali, and R. Paul, "Reasons for migration among medical students from Karachi”, Medical Education, 2008, pp. 61-68.

[15] H. Bernunger, and G. Mattsson, "Why Swedes study abroad: A study of what motivates Swedish students at Karlstad University to study abroad", (Karlstad University, Department of Economic Sciences, Communication and IT), retrieved from: http://urn.kb.se/resolve?urn=urn:nbn:se:kau:diva-1826,

(Accessed: 28 December 2008), 2008.

[16] B. Goodman, R. Jones, and M. Macias, "An exploratory survey of Spanish and English nursing students' views on studying or working abroad", Nurse Education Today, 2008, pp. 378-384.

[17] A. Kitsantas, "Studying abroad: The role of college students' goals on the development of cross-cultural skills and global understanding", College Student Journal, 2004, pp. 441-452.

[18] E.A. Akl, N. Maroun, S. Major, C. Afif, A. Abdo, J. Choucair, M. Sakr, C.K. Li, B.JB. Grant, and H.J. Schünemann, "Post-graduation migration intentions of students of Lebanese medical schools: A survey study", BMC Public Health, Vol. 8, No. 191, (8 pages), 2008, pp. 191-198.

[19] T. Gatfield, and C. Chen, "Measuring student choice criteria using the theory of planned behavior: The case of Taiwan, Australia, UK, and USA", Journal of Marketing for Higher Education, 2006, pp. 77-95.

[20] G. Davey, "Chinese students motivations for studying abroad", International Journal of Private Higher Education, [Online], 2005, pp. 16-21.

[21] Zeszotarski, P., Expectations and Experiences of International Students in an American Community College in the Context of Globalization, Doctoral dissertation, Available from: Dissertation Abstracts International Database (AAT 3089019), 2003.

[22] I. Sverko, "Students' intentions to leave Croatia: The extent of potential "brain drain" and its determinants in 1995, 1997 and 2004", Drustvena Istrazivanja, 2005, pp. 1149-1174. 
[23] L. Chen, "East-Asian students' choice of Canadian graduate schools", International Journal of Educational Advancement, [Online], 2007, pp. 271-306.

[24] T.W. Mazzarol, G.N. Soutar, D. Smart, and S. Choo, "Perception, information and choice: Understanding how Chinese students select a country for overseas study", Australian Education International, Department of Education, Training and Youth Affairs, Commonwealth of Australia, Canberra, 2001.

[25] Y. Kwon, "Factors affecting international students' transition to higher education institutions in the United States - from the perspective of office of international students", College Student Journal, 2009, pp. 1020-1036.

[26] R. Murray-Harvey, and J.P. Keeves, "Students' learning processes and progress in higher education", Paper presented at the American Educational Research Association Annual Meeting, New Orleans, L.A., Available from: ERIC Document Reproduction Service (ED374703), 1994.

[27] J. Wang, "A study of resiliency characteristics in the adjustment of international graduate students at American universities", Journal of Studies in International Education, 2009, pp. 22-45.

[28] S. Poyrazli, and P.R. Kavanaugh, "Marital status, ethnicity, academic achievement, and adjustment strains: The case of graduate international students", College Student Journal, 2006, pp. 767-780.

[29] P. Tomich, J.J. McWhirter, and W.E. King, "International student adaptation: Critical variables", International Education, 2000, pp. 37-46.

[30] Lee, J.K., An Analysis of Adaptation Factors Experienced by Korean International Students in Theological Institutions in the United States, Doctoral dissertation, Available from: Dissertation Abstracts International Database (Publisher: Southern Baptist Theological Seminary), 2002.

[31] P. Wilcox, S. Winn, and M. Fyvie-Gauld, "It was nothing to do with the university, it was just the people: The role of social support in the first-year experience of higher education", Studies in Higher Education, 2005, pp. 707-722.

[32] Surdam, J.A.C., A Study of International Student Adaptation at the University of Wyoming, Unpublished doctoral dissertation, University of Wyoming, Available from: Dissertation Abstracts International Database, 1981.

[33] A. Kaul, "Predictors of positive adaptation among international students in the United States", Dissertation Abstracts International: Section B: The Sciences and Engineering, 62(10-B). May 2002, 4790, US: Univ Microfilms International (Publisher: University of Memphis), 2001.

[34] F.J. Galloway, and J.R. Jenkins, "The adjustment problems faced by international students in the United States: A comparison of international students and administrative perceptions at two private, religiously affiliated universities", NASPA Journal, 2005, pp. 175187.

[35] Y. Zhou, and J. Todman, "Patterns of adaptation of Chinese postgraduate students in the United Kingdom", Journal of Studies in International Education, 2009, pp. 467-486.

[36] S. Zimmerman, "Perceptions of intercultural communication competence and international student adaptation to an American campus", Communication Education, 1995, pp. 321-335.

[37] C. Ward, and A. Kennedy, "Locus of control, mood disturbance and social difficulty during cross-cultural transitions", International Journal of Intercultural Relations, 1992, pp. 175-194.

[38] K. Tochkov, L. Levine, and A. Sanaka, "Variation in the prediction of cross-cultural adjustment by Asian-Indian students in the United States", College Student Journal, 2010, pp. 677-689.

[39] Hamed, S.A.E.A., An Analysis of Support Resources Used to Help Solve the Problems Faced by Egyptian Students and Their Families in the United States, Doctoral dissertation, Available from: ProQuest Dissertations \& Theses Database (UMI No. 8520112), 1985.

[40] G.R. Sodowsky, and B.S. Plake, "A study of acculturation differences among international people and suggestions for sensitivity to within-group differences", Journal of Counseling \& Development, 1992, pp. 53-59.

[41] J. Abe, D.M. Talbot, and R.J. Geelhoed, "Effects of a peer program on international student adjustment", Journal of College Student Development, 1998, pp. 539-547.

[42] T. Mazzarol, and G.N. Soutar, "“Push-pull” factors influencing international student destination choice", The International Journal of Educational Management, 2002, pp. 82-90.

[43] S. Lysgaard, "Adjustment in a foreign society: Norwegian Fulbright grantees visiting the United States", International Social Science Bulletin, 1955, pp. 45-51.

[44] K. Oberg, "Cultural shock: Adjustment to new cultural environments", Practical Anthropology, 1960, pp. 177-182.

[45] L. Brown, and I. Holloway, "The initial stage of the international sojourn: Excitement or culture shock?", British Journal of Guidance \& Counselling, 2008, pp. 3349.

[46] A.T. Church, "Sojourner adjustment", Psychological Bulletin, 1982, pp. 540-572.

[47] Maslow, A.H., Motivation and Personality, Harper \& Row, Publishers, Inc., New York, 1954.

[48] Maslow, A.H., Motivation and Personality, HarperCollins Publishers, Inc., New York, 1987. (Revised by Frager, R., J. Fadiman, C. McReynolds, and R. Cox) [49] A. Cronin, V.D. Alexander, J. Fielding, J. MoranEllis, and H. Thomas, "The analytic integration of qualitative data sources", in: P. Alasuutri, J. Brannen, and L. Bickman (Eds.), Handbook of Social Research Methods, Sage, London, 2007, pp. 572-584.

[50] A. Bryman, "Integrating quantitative and qualitative research: How is it done?", Qualitative Research, 2006, pp. 97-113.

[51] J.C. Schmidt, "Towards a philosophy of interdisciplinarity: An attempt to provide a classification and clarification", Poiesis Prax, 2008, pp. 53-69.

[52] Patton, M.Q., Qualitative Evaluation and Research Methods, (2nd ed.), Sage, Newbury Park, C.A., 1990.

[53] Tashakkori, A., and C. Teddlie, Mixed Methodology: Combining Qualitative and Quantitative Approaches, Sage, Thousand Oak, C.A., 1998.

[54] Creswell, J.W., Research Design: Qualitative, Quantitative, and Mixed Methods Approaches, (4th ed.), Sage, Thousand Oaks, C.A., 2014. 
International Journal of Technology and Inclusive Education (IJTIE), Special Issue Volume 2, Issue 1, June 2015

[55] W. Wu, and M. Hammond, "Challenges of university adjustment in the UK: A study of East Asian Master's degree students", Journal of Further and Higher Education, 2011, pp. 423-438.

[56] K. Yan, and D.C. Berliner, "Chinese international students' academic stressors in the United States", College Student Journal, 2009, pp. 939-959. 